\title{
As vilas de índios dos sertões do norte e do estado do Maranhão: desenho, território e reforma urbana no século XVIII ${ }^{1}$
}

\author{
The indigenous's towns of northern sertões and Maranhão state: \\ drawing, territory and urban restructuring in 18th century
}

Esdras Araujo Arraes ${ }^{2}$

RESUMO

Em decorrência da política de Sebastião José de Carvalho e Melo, futuro marquês de Pombal, um novo paradigma urbano apareceu nos sertões do Norte por meio da criação de vilas de índios voltadas à civilização dos nativos segundo os modelos do lluminismo europeu. Logo, o objetivo deste ensaio é refletir sobre o efeito que as vilas de índios trouxeram à urbanização das zonas interiorizadas das capitanias do Norte, assim como interpretar o desenho urbano à luz das cartas régias (e outros documentos oficiais) de fundação de vilas e dos encontros culturais realizados entre indígena e europeu. Pretende-se, ainda, demonstrar que a forma urbis adquirida por esses núcleos urbanos apresentou vestígios tanto da normativa estética do século das Luzes como da cultura nativa resignificada pelo adventício.

Palavras-chave: Iluminismo. Índio. Urbanismo. Urbanização. Vila.

\section{ABSTRACT}

Owing to Sebastião José de Carvalho e Melo's policies, a new urban paradigm has appeared at Brazilian Northern hinterlands (sertões) by means of Indian's town creation in order to civilize native people according to European Enlightenment models. Thus the aim of this paper is think of the effect that Indian's towns has brought to the sertões's urbanization as well as interpret its urban morphology in light of royal letter (or another official document) of towns foundation and cultural encounters have taken place between indigenous and European. Also it seeks to demonstrate that urban morphology acquired by those towns has presented trace elements both Enlightenment aesthetical normative as native culture re-meaning by adventitious.

Keyword Enlightenment. Indians. Urbanism. Urbanization. Town.

\footnotetext{
${ }^{1}$ Trabalho financiado pela Fundação de Amparo à Pesquisa do Estado de São Paulo - FAPESP (processo no 2013/04404-9)

${ }^{2}$ Faculdade de Arquitetura e Urbanismo da Universidade de São Paulo-USP.
} 


\section{$A$ rede de vilas de índios dos sertões do Norte e do Estado do Maranhão}

Por carta de 24 de janeiro de 1725, o vice-rei do Estado do Brasil, Vasco Fernandes César de Menezes, lembrava o rei, D. João V, a urgência de multiplicar as vilas nos sertões do Norte3. Para o representante da Coroa, prevalecia a ideia de que povoações oficiais converteriam os sertões "indômitos" em territórios "obedientes", livres das injustiças e dos problemas sociais que motivavam toda a sorte de fraude (AHU-Bahia, Cx. 21, D. 1842). A mesma opinião compartilhava o procurador da Coroa, Pedro Gonçalves Cordeiro, o qual, em consulta de 5 de julho de 1746, reconhecia os benefícios das vilas nos "certoens", "para melhor comodo dos moradores, e se evitarem os muitos insultos, que nelles se cometem quotidianam..$^{\text {te }}$ sem haver remedio p $^{\text {a }}$ tanto mal" (AHU-Bahia, Cx. 29, D. 2978). Ambas as autoridades viam na fundação de vilas a propagação de um sistema urbano ideal e coeso, habilitado a beneficiar os povos e o território.

Em 1756, havia 13 vilas nos sertões das capitanias do Norte $^{4}$. Esse número retrata o cuidado da Coroa portuguesa em reformar espaços tidos pela historiografia brasileira clássica como periféricos ou pouco partícipes das agendas administrativas do rei. A preocupação da Coroa ao criar povoações nos sertões voltava-se, sobretudo, a aplicar a justiça nos territórios onde o adensamento populacional justificasse e que estivessem afastados das sedes de comarca, fragilizados pela arbitrariedade dos "juízes da terra" dos julgados por vezes propensos a favorecer a sua rede de relações tecida localmente. As vilas seriam a mediação ideal para equilibrar a administração da justiça em espaços reformados e hierarquizados pela Câmara, centro simbólico da autonomia municipal. Nesse sentido, aquelas vilas fundadas ao longo do Setecentos representavam a aspiração da transformação ética dos sertões, de locus de tensão em territórios direcionados à "felicidade dos povos", trazendo-lhes esperança em meio às adversidades cotidianas.

Em paralelo, os sertões do Norte de meados do século XVIII assistiram a outra modalidade de reforma socioespacial, centrada na civilização dos índios em vilas cujos projetos ex nihilo preconizavam, sob a égide ideológica do Iluminismo europeu, a retirada da "barbárie" impondo-lhes normas morais de civilidade. A conversão dos nativos em vassalos

\footnotetext{
${ }^{3} \mathrm{Em}$ termos gerais, os sertões do Norte eram a grande área que circunscrevia as regiões interiorizadas das capitanias do Norte, as quais incluíam as capitanias de Pernambuco e suas anexas (Ceará Grande, Rio Grande, Paraíba e comarca de Alagoas), Sergipe del Rei e Bahia. Já os sertões do Estado do Maranhão envolviam os da capitania homônima e a do Piauí. ${ }^{4}$ Penedo (1636), Itabaiana (1667), Lagarto (1698), Mocha (1712), Jacobina (1721), Rio de Contas (1724), Itapicuru de Cima (1726), Inhambupe (1726 - depois o título foi transferido para a povoação de Água Fria), Vila Nova do Rio São Francisco (1732), Icó (1736), Aracati (1746), Urubu (1748), Barra (1753).
} 
apresenta outras interpretações possíveis na chave político-econômica. Conforme Renata Malcher de Araujo (2010, p. 190), o índio "civilizado" cumpriu um importante papel político, "por não implicar um inimigo interno, por integrar em termos numéricos e populacionais o quadro da colônia e por, literalmente, a vir a defender dos inimigos externos", mas garantindo "a sua inserção no quadro fiscal do reino de que até então estava excluído".

Inicialmente, a implantação de vilas de índios se enquadrou na conjuntura política de definição e demarcação das fronteiras interimperiais entre a América portuguesa e castelhana. A fragilidade das fronteiras se evidenciava por existirem poucas povoações oficiais (vilas ou freguesias). Na capitania de Mato Grosso havia uma única vila (Cuiabá) em 1747, ano em que foram iniciadas as negociações diplomáticas do Tratado de Madri (1750). Na realidade, os anos que sucederam a assinatura do Tratado de Madri, Sebastião José de Carvalho e Melo $^{5}$ (conde Oeiras e futuro marquês de Pombal) e Francisco Xavier de Mendonça Furtado ${ }^{6}$ articularam geoestratégias precisas de cunho restaurador e reterritorializador (DERNTL, 2010, p. 34), visando a afirmação da soberania portuguesa sobre o espaço e as sociedades coloniais. Isso exigia a expansão da rede administrativa, tanto civil quanto eclesiástica, em regiões ainda de fraca presença estatal (KANTOR, 2010, p. 305). O Estado do Grão-Pará e Maranhão consistiu no primeiro território em que foram ensaiados e concretizados os projetos de reestruturação sócio-espacial de Carvalho e Melo e Mendonça Furtado.

Com efeito, a chegada de Mendonça Furtado a Belém, em 1751, agora como governador e capitão-general daquele Estado, impulsionou a urbanização da Amazônia por meio da execução de um projeto concebido para impor o poder da Coroa sobre as fronteiras em disputa. Ele ficou encarregado de criar povoações civis, as vilas, em oposição às aldeias missioneiras, de caráter eclesiástico, celebrando seu papel simbólico enquanto sítio de vida civilizada (ARAUJO, 1998, p. 117). Na escala macro, o desenho daquele grande território foi reconfigurado a partir da fundação da capitania de São José do Rio Negro, em 3 de março de 1755, com capital sediada na vila de São José (DELSON, 1997, p. 51). Em 1758, o governo do Piauí foi autonomizado, e a capitania rebatizada de São José do Piauí, toponímia panegírica à figura do rei D. José $\mathrm{I}$. O projeto procurou, também, determinar com a máxima precisão possível os limites territoriais entre as capitanias que formavam o Estado do Grão-Pará e Maranhão. Em missiva ao governador do Maranhão, Mendonça Furtado admitia ser "indispensavel determinar os lemites destas Capp. ${ }^{\text {nias }}$, para que o futuro não fique razão algúa de discordia, e saberem tão bem os Menistros dellas athe donde se lhes estende a sua jurisdição" (Biblioteca Nacional de Portugal. Colecção Pombalina).

Os planos de reforma de Carvalho e Melo alcançaram outras instituições. Ainda em 1755, foi criada a Companhia Geral de Comércio do Estado do Grão-Pará e Maranhão com o

\footnotetext{
${ }^{5}$ Sebastião José de Carvalho e Melo foi, antes de se tornar o paradoxal marquês de Pombal, ministro do rei D. José I.

${ }^{6}$ Meio-irmão de Sebastião José de Carvalho e Melo.
} 
objetivo de desenvolver a agricultura, o comércio e a venda de escravos africanos em substituição à mão-de-obra indígena. $O$ trabalho indígena e sua liberdade pautaram diversos decretos e cartas régias ao longo dos séculos XVI, XVII e XVIII, não cabendo, aqui, explorálos com profundidade ${ }^{7}$. Convém exemplificar, no entanto, que a Bula de Benedito XIV, de 1741, enviada a todos os bispos do Brasil e outros domínios da Coroa portuguesa, condenou a escravização do índio por "pessoa, ou seja secular, ou ecleziastica de qualquer estudo, sexo, grão-condição, e dignidade...nem attende daqui em diante...vendellos, comprallos, trocallos, ou dallos" (Arquivo Nacional da Torre do Tombo, Casa de Suplicação, liv. 33). As Ordens Religiosas, particularmente a Companhia de Jesus, "administradores" no temporal e no espiritual dos índios aldeados, tiveram seu poder pastoral fragmentado por parte de Mendonça Furtado.

Decorreu daquela Bula a escrita da lei de 6 de junho de 1755, que estabeleceu a liberdade dos índios no Estado do Grão-Pará e Maranhão, assim como do alvará de 7 de junho do mesmo ano, por meio do qual os indígenas ficaram sob os cuidados "no temporal aos governadores, ministros e às justiças seculares, com inibição das administrações dos Regulares, derrogando todas as leis, regimentos, ordens e disposições em contrário" (BELLOTO, 1988, p. 58). O alvará reforçou que "ficarão incorporados os referidos Indios sem distincção, ou excepção alguma, para gozarem de todas as honras, privilegios, e liberdades, de que meus Vassallos gozão actualmente conforme as suas respectivas graduaçõens e cabedais" (LEY, 1755). A ordem era bastante clara ao posicionar os índios, em termos ideais, em paridade com os colonos portugueses. Aliás, ambos os documentos concordavam com a segunda "Instrução" secreta passada a Mendonça Furtado, que havia apresentado, como melhoria da América portuguesa, a concessão da liberdade indígena e a redução do poder dos jesuítas sob os índios e o espaço (RODRIGUES, 1999, p. 100). Por seu turno, os inacianos reagiram fortemente às leis que restituíam aos índios sua liberdade, andando publicamente a pregar contra a normativa régia e a conclamar a quem possuísse escravos a opor-se às deliberações (ALMEIDA, 1997, p. 153).

A expressão máxima das políticas indigenistas veio com a publicação do Directorio que se deve observar nas povoaçoens dos índios do Pará, e Maranhaõ, equanto Sua Magestade nã̃ mandar o contario, redigido por Mendonça Furtado, em 3 de maio de 1757, confirmado por D. José I em 17 de agosto de 1758 (DIRECTORIO..., 1758). Tratava-se de um código ideológico que sistematizou o pensamento e a ação do governador do Grão-Pará durante sua experiência de implantar vilas e promover o reconhecimento e delimitação territorial da Amazônia, em vista da impossibilidade de contar com a ajuda dos missionários na concretização do plano de conversão das aldeias em vilas (RODRIGUES, 1999, p. 108). O Diretório previa a cessão da Companhia de Jesus - ou quaisquer Ordens regulares contrárias ao código - do controle total e completo sobre os índios aldeados em suas missões.

\footnotetext{
${ }^{7}$ Sobre o tema, recomenda-se a leitura do trabalho de Heloísa Liberalli Belloto (1988).
} 
O Diretório dos Índios é composto de 95 parágrafos, cujos temas circunscrevem questões diversas, sejam culturais, econômicas, administrativas, urbanas ou éticas. $O$ primeiro parágrafo criava o cargo de "Diretor", oficial obrigado a civilizar os índios de maneira diretiva, nunca coercitiva, devendo ser de "bons costumes, zelo, prudencia, verdade, sciencia da língua, e de todos os requisitos necessarios para dirigir com acerto o referidos Indios debaixo das ordens, e determinações" (DIRECTORIO..., 1758, p. 6). O projeto de civilização envolvia o ensino da língua portuguesa (em detrimento da "língua geral" inventada pelos jesuítas) e a "fabricação" de casas unifamiliares "á imitação dos Brancos; fazendo nellas diversos repartimentos, onde vivendo as Familias com separação, possaõ guardar, como Racionaes, as Leys da honestidade, e policia" (DIRECTORIO..., 1758, p. 36). Tais normas de conduta incluíam o incentivo ao casamento entre colonos e índios, recusando insistentemente a poligamia, abominada como inimiga das "Naçõens mais polidas do Mundo" (DIRECTORIO..., 1758, p. 36). Nesse aspecto, Renata Araujo (2003, p. 161) pôs luz em facetas obscurecidas no discurso ideológico do Diretório. De acordo com a autora, eram os colonos (e não os índios) que precisavam ser convencidos da igualdade de direitos, mudando os hábitos, inclusive casando-se com os índios, no intuito de eliminar o preconceito e a discriminação sofridos pelos nativos, bem como incorporando suas terras pelo legítimo instituto do matrimônio.

As vilas de índios, tal como os demais núcleos urbanos de mesmo status político, eram administradas por juízes ordinários, vereadores (de preferência metade índios e metade portugueses) e mais oficiais de justiça. Rita Heloísa de Almeida (1997, p. 183) e Beatriz Perrone-Moisés (1992, p. 118) comentam que a integração dos índios no quadro dos oficiais da Câmara tendia a preparar a sociedade para a aceitação harmoniosa de ser administrada por nativos. No caso de o indígena cometer delito, os juízes e os "Principais" seriam advertidos e o culpado castigado publicamente, mas com "suavidade, e brandura, que as mesmas Leys permitirem, para o horror do castigo (o) não obrigue a desamparar as suas Povoaçoens, tornando para os escandalosos erros da Gentilidade" (DIRECTORIO..., 1758, p. 2). Se a vila não possuísse o terreno para o sustento da comunidade, o Diretor deveria remeter uma carta ao governador solicitando a parcela de terra necessária, "situada no continente das mesmas Povoaçoens" (DIRECTORIO..., 1758, p. 8). O projeto de civilização investia na agricultura e no comércio. Quanto às práticas religiosas, em cada povoação haveria um padre secular responsabilizado sobretudo de ensinar as regras do catolicismo aos novos vassalos do rei.

Não havia no texto do programa ideológico do Diretório ordens explícitas quanto à forma das vilas ou relativas à implantação. Entretanto, reiterava recomendações comuns aos concelhos em geral. O parágrafo 74 instruía que os Diretores recém-chegados na povoação deveriam providenciar a construção das casas de Câmara e das cadeias, "cuidando muito que estas sejão erigidas com toda a segurança, e aquellas com a possível grandeza" (DIRECTORIO..., 1758, p. 32). Há uma nítida aproximação entre os parágrafos 12 e 74, pois este 
advertia aos Diretores que persuadissem os índios a edificar suas casas decentes, "desterrando a vileza de viver em choupanas á imitação dos que habitão como barbaros o inculto centro dos Sertoens". O Diretório distinguia, assim, por meio da arquitetura, a alteridade dos índios impelidos à civilização, isto é, aqueles "bárbaros" ou "selvagens" habitantes de choupanas "indecentes".

Foi devido ao Diretório que os sertões do Norte se enquadraram num novo panorama urbano. A legislação pombalina foi categórica em converter todos as aldeias missioneiras à condição de vila ou freguesia e os índios de seu estado "selvagem" em vassalos civilizados. Segundo Araujo (2013, p. 98), mudava-se um importante paradigma, assumindo como urbano não só os aspectos formais da vila - ainda que frágeis e insuficientes -, mas também aqueles que lá estava.

As primeiras vilas localizavam-se na capitania do Maranhão - Monção (1757), Viana (1757) e Viçosa de Tutóia (1758), antes aldeias de São Francisco Xavier do Carará, Maracu e Nossa Senhora da Conceição de Tutóia. Além das vilas, foram criados os "lugares" de índios de Lapela (1757), Lapa (1758), São Mamede (1758), Trezedelas (1758) e Araioses (1759). Na semântica do Setecentos, "lugar" seria uma povoação pequena, cuja hierarquia residia no intervalo entre a aldeia e a vila: "he menos que villa, \& mais que aldea" (BLUTEAU, 1728, p. 202). A lógica observada pelos decretos régios tomou como base a densidade populacional das aldeias - aquelas com maior concentração humana, "faça erigir em villas... e as mais pequenas em lugares" (REGISTRO..., 1891, p. 82). Os "lugares" não eram sedes de freguesia, mas em compensação a Coroa encaminhou um Diretor e um pároco secular como "agentes da civilização" indígena.

Por carta régia de 8 de maio de 1758, enviada ao conde dos Arcos, D. José I estendeu a legislação do Diretório ao Estado do Brasil, erigindo as aldeias, "que hoje tem, e no futuro tiverem os referidos índios", em vilas ou lugares (AHU-Bahia, Cx. 20, D. 3634). No mesmo dia, outra carta foi dirigida ao arcebispo da Bahia, formalizando paróquia (com o título de vigararia) em cada vila instalada. Os vigários seriam preferencialmente clérigos seculares do Hábito de São Pedro, para evitar os "referidos inconvenientes, e do grave escrúpulo, que necessariamente se devia de reter os mesmos Religiozos separados da sugeição aos seus Superiores Regulares" (AHU-Bahia, Cx. 20. D. 3635). Em setembro de 1758, o conde dos Arcos dava conta a Sebastião José de Carvalho e Melo sobre o andamento dos trabalhos de elevação das aldeias e introdução dos padres seculares nas vilas. As autoridades envolvidas nos trabalhos deveriam enviar informações "individuaes de cada huma das Aldêas e qualidade e extenção das Fazendas que lhe ficão em circuito, se não possuídas por alguem ou devolutas; e assim tãobem o numero de cazaes, de que se compunha cada huma dellas..." (AHU-Bahia, Cx. 20, D. 3634). O objetivo das informações consistia em averiguar se existiam sesmarias não cultivadas, bem como inventariar o patrimônio fundiário das Ordens religiosas e sua capacidade de produção no intuito de garantir o rendimento das novas Câmaras. 
Foram instituídas nos sertões de Baixo das capitanias da Bahia e de Sergipe del Rei as vilas de Abrantes (1758), Mirandela (1758), Tomar (1758), Pombal (1758) e Soure (1758), antes missões jesuíticas do Espírito Santo, Sacos dos Morcegos, Gerú, Canabrava e Natuba. Em 14 de setembro de 1758, uma carta régia com o mesmo conteúdo daquela enviada ao conde dos Arcos chegou a Luis Diogo Lobo da Silva, governador da capitania de Pernambuco e anexas, informando-o das novas leis que determinavam a transformação das aldeias jesuíticas em vilas e vigararias (LOPES, 2005, p. 102). A execução das ordens foi levada a cabo, em princípios de 1759, pelo ouvidor geral Bernardo Coelho da Gama Casco. As seis vilas fundadas nesse ano distribuíram-se entre as capitanias anexas do Ceará e Rio Grande. Para a primeira, surgiram Vila Viçosa Real (missão da Ibiapaba), Soure (missão de Caucaya), Arronches (aldeia de Parangaba) e Messejana (missão da Paupina). No Rio Grande as autoridades elevaram a vila de Extremoz (aldeia do Guajarú) e Arez (missão dos Guarayras) (Fundação da Biblioteca Nacional, Localizador: I-12, 3, 34).

Os anos que sucederam a extinção da Companhia de Jesus no Reino e domínios ultramarinos de Portugal (3 de setembro de 1759) foram acompanhados pelo crescente número de vilas de índios em diversas zonas de presença jesuítica. A vigilância incidiu ainda sobre aldeias missioneiras administradas por capuchinhos e oratorianos. De acordo com a Fátima Martins Lopes (2005, p. 132), em 1760 foi enviado um aviso do novo secretário de estado da Marinha e Ultramar, Francisco Xavier de Mendonça Furtado, a Luis Diogo Lobo da Silva, instituindo que em todas as missões da capitania de Pernambuco, de qualquer ordem religiosa, fossem convertidas em vila. Dessa forma, apareceram no contexto da urbanização das capitanias do Norte 13 novos núcleos urbanos: Ceará Grade - Montemor o Novo da América (1760, aldeia da Palma) e Vila Real do Crato (1762, missão do Miranda); Rio Grande Portalegre (1761, missão do Apodi), São José de Mipibu (missão capuchinha de Mipibú) e Vila Flor (1762, missão de Igramació); Paraíba - Pilar (1763), Conde (1764) e Alhandra (1765); comarca de Pernambuco - Santa Maria (1761), Assunção (1761) e Simbres (1762); Alagoas Atalaia (1763); capitania da Bahia - Pedra Branca (1761).

É curioso que, enquanto as primeiras medidas do Diretório destinaram-se à capitania do Maranhão, a maior incidência da modalidade "vila de índios" aconteceu no grande território da capitania de Pernambuco e, neste particular, fruto do empenho administrativo do governador Lobo da Silva. De fato, a "Carta Topographica aonde se compreendem as Capitanias de que se compoem ao prezente o Governo de Pernambuco" (figura 1), desenhada em 31 de março de 1766, possivelmente por José Gonsalves da Fonseca, retrata a rede de povoações de Pernambuco hierarquizada em cidades, vilas e lugares de índios.

Cabe destacar que o mapa foi dedicado a Mendonça Furtado. Este, por seu turno, havia recomendado a Lobo da Silva, em 1758, que cumprisse as "intenções de V. Mag. ${ }^{\text {e reduzindo }}$ todos estes povos a christãos e civis, livrandose intr. ${ }^{a} m .{ }^{\text {te }}$ da brutalidade miséria, e tirania com q' athé agora erão tratados pelos seus Administradores" (Biblioteca Nacional de 
Portugal. Colecção Pombalina). A imagem cartográfica cristalizou as ordens de Mendonça Furtado de cumprir cabalmente os princípios ideológicos do Diretório dos Índios em outros territórios del rei, sedimentando o ambicioso projeto de reformar e civilizar os sertões. No texto lateral do mapa, o governador assegurou que Pernambuco,

[...] no prezente tempo, devedor no aumento das suas Povoaçoens ao Diretorio estabelecido, e propagado já com antecipação por V. Ex. ${ }^{a}$ nos Estados do Gram Pará, e Maranhão...pelo qual se converterão nestas Capitanias as antigas Aldeas em novas Vilas, q' nesta carta vám signaladas nas posituras em que existem. (Gabinete de Estudos Arqueológicos de Engenharia Militar, Mapoteca, doc. 4586-3-38-5).

Isto é, para além dos feitos de Lobo da Silva, a imagem cartográfica e as vilas de índios representavam por si um discurso laudatório ao escritor do Diretório, sem o qual inexistiria o novo panorama urbano da capitania de Pernambuco e suas anexas.

Figura 1 - CARTA Topographica aonde se compreendem as Capitanias de que se compoem ao prezente o Governo de Pernambuco; oferecida ao Ill. ${ }^{\mathrm{mo}}$ e Ex. ${ }^{\mathrm{mo}} \mathrm{S} .{ }^{\mathrm{r}}{ }^{\text {Fran }}{ }^{\mathrm{co}}{ }^{\mathrm{X}}$. de M. ${ }^{\mathrm{ca}}$ Furtado, do Conselho de S. Mag. ${ }^{\text {e }}$ Fidelissima, Ministro, e Secretario de Estado da Marinha e Conquistas, 1766, por José Gonsalves da Fonseca.

Fonte: Gabinete de Estudos Arqueológicos de Engenharia Militar(GEAEM). Direção de Serviços de Engenharia. Mapoteca, Doc. 4586-3-38-5. 
A normativa régia de 8 de maio de 1758 regulamentava a conversão semântica das denominações das aldeias missioneiras elevadas à categoria de vila: "as quaes determineis com os nomes dos Lugares, e Villas destes Reinos que bem vos parecer, sem atenção aos nomes bárbaros, que tem actualmente" (AHU-Bahia, Cx. 20, D. 3634). Urbanizavam-se os sertões do Brasil colonial com toponímias que funcionavam como simulacros da rede urbana metropolitana (KANTOR, 2010, p. 307). Foram utilizados os nomes das vilas do Reino, da Casa de Bragança, da Coroa, do Infantado, da Ordem de Cristo e algumas da casa do marquês de Pombal. A duplicação toponímica reafirmava a pertença destas vilas a um território que seria inquestionavelmente português (ARAUJO, 2010, p. 190). Por outro lado, "a conversão toponímica não apenas eliminou os nomes indígenas dos antigos aldeamentos, como eliminou, em tese, a própria ideia de aldeamento", um espaço ambíguo e de transição, transformado em urbano depois de efetivadas as ordens do Diretório (ARAUJO, 2010, p. 190).

A implantação de vilas de índios nos sertões do Norte regrediu a partir de 1762. Porém, os "lugares" passaram a ser preferidos, aparecendo, inclusive, nas primeiras décadas do século XIX. A maioria localizava-se nas capitanias do Maranhão e Piauí: Cajoeiro (1766), Brejo dos Anapurus (1766), Amanajós (1766), São João de Sende (1766), Nossa Senhora da Conceição dos Índios Arayós (1766), São Gonçalo do Amarante (1772), Penalva (1784), São Félix das Balsas (1787), Cajari (1815) e Almeida del Rei (1820). Sabe-se que em Pernambuco havia seis lugares: Águas Belas (1762), Porto Real do Colégio (1763), Barreiros (1763), Almofala (1766), Aricobé (1766) e Arneirós (1766).

Os lugares de São João de Sende e Cajoeiro foram estabelecidos pelo governador do Piauí, João Pereira Caldas. O primeiro reuniu 558 índios Guegués e Acaroás (AHU-Piauí, Cx. 9, D. 563), enquanto que o segundo congregou a etnia Jaicó. Para Cajoeiro, Pereira Caldas instituiu como Diretor "hum soldado chamado Manoel Alz' de Araujo, e alem das ordens com que o instrui, lhe determinei que prontamente fizesse recolher, e reconduzir á dita Povoação todos os índios, que dalli se achassem aubsentes" (AHU-Piauí, Cx. 10, D. 589). Em 1766, o então governador do Maranhão, Joaquim de Melo e Póvoas, fundou a povoação dos índios Amanajós "em hum terreno ao pé de hum riacho" (Arquivo Nacional da Torre do Tombo, Ministério do Reino, mç. 601, cx. 704, n. 72), assim como o Brejo dos Anapurus, onde havia posto um novo Diretor, e o lugar de Nossa Senhora da Conceição dos índios Arayós. A localização do lugar de Amanajós suscita algumas perguntas: quais aspectos do território foram levados em consideração na escolha da localidade onde seriam implantados os lugares e as vilas de índios? Como a forma das povoações representou, nas esferas simbólica e ideológica, a pretendida civilização indígena? Vejamos como a documentação aborda essas interrogações e contempla o "encontro cultural" entre o "território indígena", o das ordens religiosas e o das políticas de urbanização da Coroa portuguesa. 


\section{O sítio, o território e o desenho das vilas de índios: alguns exemplos}

Quando convertida a missão religiosa em vila, o núcleo urbano ou permanecia no local da aldeia - desde que feitas as devidas readequações formais no traçado e na arquitetura ou era assentado nas proximidades da antiga povoação indígena que lhe conferiu razão de ser. Cabia às autoridades régias responsáveis pela elevação decidir sobre a realocação da vila, privilegiando, em geral, os espaços de vivência indígena. As considerações de Rubens Gianesella (2008), pautadas na Arqueologia, parecem oportunas, mesmo tratando de vilas litorâneas paulistas sem vinculação com as aqui em causa. Para o autor, as aglomerações oficiais raramente partiram do zero, sequenciando as preexistências indígenas marcadas por relações entre o homem e a natureza e, portanto, vitais à sobrevivência de qualquer povoação (GIANESSELA, 2008, p. 125). Embora representasse a reafirmação da Coroa portuguesa no espaço, as vilas de índios afirmavam o papel do nativo na construção da localidade, incorporando seus saberes nos processos de transformação territorial.

A vila de Assunção é caso exemplar, sendo erigida, em 24 de setembro de 1761, numa das ilhas do rio São Francisco pelo ouvidor da comarca de Alagoas Manoel Gouvea Alvarez. Naquela ocasião, estavam presentes o Diretor dos índios designado, José Francisco Pinho, o capitão mor, Pedro da Fonseca de Souza, e outras pessoas da circunvizinhança. Esses agentes e "mais índios da antiga aldeia" decidiram erigir a vila na ilha de Pambú, "por ser a ditta ilha nesse destricto a que tem as qualidades e circunstancias mais attendiveis para ficar nella estabelecida a Villa, e não na Ilha da Vargem" (Fundação da Biblioteca Nacional, Localizador: I - 12, 3, 34).

Ora, em 1672, o capuchinho Martinho de Nantes havia sido estimulado por Francisco Rodrigues a se instalar na ilha de Pambu, "onde havia uma bonita aldeia de cariris" (NANTES, 1979, p. 36), a fim de erigir uma aldeia de catequização daquela etnia. Em 1739, existia uma aldeia missioneira em Pambu de índios Cariris dedicada à Nossa Senhora da Conceição, contendo 100 fogos e administrada por outro capuchinho, Frei Angelo das Chagas (AHU-Pernambuco, Cx. 55, D. 4767). De acordo com as prospecções arqueológicas realizadas por Gabriela Martin, "o grupo de missionários que iniciaram a evangelização do sertão do São Francisco instalaram-se nas áreas onde já existiam aldeias estabelecidas de índios sedentários dedicados à agricultura e que estavam situados, principalmente, nas ilhas fluviais de solo mais fértil" (MARTIN, 1990, p. 171). A arqueóloga continua: “o estabelecimento das aldeias indígenas precedeu a implantação das missões nos mesmos lugares e não o contrário" (MARTIN, 1990, p. 171). 
A missão de Pambu e o território da antiga aldeia cariri foram resignificados pelos representantes da Coroa na criação da vila de Assunção: "no lugar da dita Ilha do Pambu, inda existe a Igreja, e vestigios da antiga aldeia da Ilha para onde se mudarão o dito Diretor, e os Principaes, e mais indios que se achão agregados nesta ilha da Vargem" (Fundação da Biblioteca Nacional, Localizador: I - 12, 3, 34). Por sua vez, a ilha da Vargem foi considerada inconveniente à civilização indígena em razão de ser "muito esteril de pastos para os gados, e de todo o genero de madeiras, e carece de terras bastante apta para as lavouras, plantas, e rossas de todos os moradores" (Fundação da Biblioteca Nacional, Localizador: I - 12, 3, 34), e ter "só trez legoas de comprido, e meya de largueza". Inversamente, Pambu era "a mayor (ilha) deste território, que tem cinco legoas, ou mais de comprido, e huma de largura, e muita fertilidade de pastos, e se conserca ainda no prezente ano, sendo de grande seca, e tem madeiras capaz de servirem aos moradores para edificarem suas cazas" (Fundação da Biblioteca Nacional, Localizador: I - 12, 3, 34). No caso das duas vilas de índios erigidas em ilhas do rio São Francisco - Assunção e Santa Rita - a própria ilha configurou o termo do concelho e o patrimônio da Câmara, ambos se confundindo com os contornos insulares.

A vila de Assunção é uma criação ex nihilo, cujo direcionamento espacial e o "desenho por escrito", redigido nas ordens do governador de Pernambuco Luís Diogo Lobo da Silva, foram enviados ao corregedor da comarca de Alagoas, Manoel Gouvea Alvarez, que ficou incumbido de implantar a vila segundo as normas expedidas de Recife. O ouvidor verificou que a ilha de Pambu comportava os atributos físicos e naturais cômodos ao erguimento do núcleo urbano. Ao contrário da ilha da Vargem, "pois se acha nella húa pequena Aldea, de poucas e pobres cazaes de índios, sem outros moradores brancos, o que tudo conduz, a fazer preciza, e necessária a mudança da gente que se acha nesta" (Fundação da Biblioteca Nacional, Localizador: I - 12, 3, 34). Coube a Gouvea Alvarez deliberar sobre o traslado dos índios de uma ilha a outra. Pambu distinguia-se como espaço de felicidade, "pois vivendo em tam louvavel união os Indios agregados das diversas Aldeas do Araxá, da Nação Porcaz e Brancarauz, com outros que andavão disperos quando não habitavão o Brejo da Gama" (Fundação da Biblioteca Nacional, Localizador: I - 2, 3, 35). Os aspectos mencionados encaminhavam a povoação ao progresso social e urbano aspirado pelo Diretório dos Índios.

Ao Diretor coube a demarcação do "espaço de terra para as cazas, e quintaes, fazendo com que fiquem todas com igoaldade, e a mesma boa perspectiva, e as ruas todas direitas e largas, e a Praça espaçosa...deixando sempre largura, o bom terreiro junto da Igreja, levantandosse logo o Pelourinho, Casa de Camera, de audiência, e Cadea" (Fundação da Biblioteca Nacional, Localizador: I - 2, 3, 35). O discurso presente nessa passagem não é inovador, mas aparece em quase todas as cartas régias de fundação de vilas emitidas por D. João V e D. José I. Aliás, os termos empregados são sempre os mesmos: ruas diretas e largas, praça central, entre outros. Com respeito à forma da vila encontra-se representado o ideal de civilização almejado, simplificando a uniformidade das casas e a regularidade do conjunto em boa ordem e bom governo. Nesse sentido, um dos traços de civilização era a igualdade 
dos povos visivelmente apreendida no desenho das povoações, permitindo, por analogia, associar a "formosura" da vila à ordem social pretendida.

Sem dúvida, a vila Viçosa Real, antes missão jesuítica da serra da Ibiapaba, é outro caso emblemático dos acordos estabelecidos entre índios e colonizadores materializados no local de implantação da aldeia e, posteriormente, da vila e determinação do termo.

Em 1660, o padre Antônio Vieira havia chegado à serra da Ibiapaba, onde os jesuítas Pedro Pedrosa e Antônio Ribeiro catequizavam muitos neófitos da etnia Tabajara, distribuídos em 20 povoações (LEITE, 1945, p. 27). Durante a subida, Vieira testemunhou focos de excelentes águas para consumo. Viu que os índios viviam da caça, do cultivo da mandioca, da plantação de alguns legumes e do mel, espesso e escuro, produzido pelas abelhas "tobí" (PAPAVERO et al., 2011, p. 133).

João da Maia da Gama, quando havia deixado a administração do Estado do Maranhão e Grão-Pará, visitou a aldeia da Ibiapaba em 1728, deixando um relato minucioso das paragens visitadas em seu itinerário realizado de São Luís a Recife pelo interior das capitanias do Norte. Em Ibiapaba, Gama descreveu os aspectos utilitários e a fertilidade da terra do promontório, dos quais as comunidades se valiam já que "produzem exscellentemente todo o genero de legumes, de mandiocas batatas, e tudo o mais que nella plantão" (MARTINS, 1944, p. 60). A intenção do padre Vieira, contudo, relacionava-se em congregar os povos das 20 aldeias "em uma só grande, com igreja capaz para todos" (LEITE, 1945, p. 27). Tal anseio foi concretizado, em 1700, por efeito dos empenhos do jesuíta Ascenso Gago, que ali fundou definitivamente a missão de Nossa Senhora da Assunção da Ibiapaba. A escolha do lugar foi negociada com os principais das três tribos reunidas no aldeamento desenhado em forma regular em torno de um grande terreiro com ruas bem delineadas (LEITE, 1945, p. 64).

Em 1759, ano da conversão da missão em vila, os representantes da Coroa, incumbidos da elevação e determinação da forma do núcleo urbano, optaram por erguê-la nas circunvizinhanças do antigo aldeamento definido por Gago e os líderes das tribos aldeadas. O mestre piloto, Manoel Rodrigues dos Santos, acompanhou o ouvidor geral de Pernambuco, Bernardo Coelho da Gama Casco, e juntos com o novo Diretor, demarcaram e dividiram a vila no terreno, seguindo as lógicas de "arruação" divulgadas pelas cartas régias e autos de criação. Rafael Moreira (2003, p. 16) explica que o termo "arruar" significa alinhar, traçar a direito um percurso arruado direcionado em linha reta ou retilínea. De fato, o desenho de vila Viçosa seguiu os padrões geométricos de regularidade e os conceitos de espacialidade do Iluminismo, tomando emprestado do Renascimento a técnica de idealizar “cidades" (ARAUJO, 1998, p. 64).

Ainda na capitania do Ceará Grande, a implantação da vila de Montemor o Novo da América ocorreu em espaços herdados dos indígenas. Os Autos de elevação da missão da Palma identificam a "povoação de aldeia e antiga missão" como o local no qual seria 
demarcado no chão o desenho da vila de Montemor (REGISTRO..., 1891, p. 82). Experiências visuais e o exame dos arredores feitos pelo ouvidor da comarca, Victorino Soares Barbosa, e pelo engenheiro Custódio Francisco de Azevedo, corroboraram a escolha (REGISTRO..., 1891, p. 265). Logo, os parâmetros de conveniência, aqui particularmente relativos às características geográficas do terreno, à comodidade e utilidade da área para a sobrevivência dos moradores, prevendo a expansão social e material da povoação, recaíram em territórios de escolha pregressa, moldados pelas experiências espaciais dos indígenas. Curiosamente, as sutilezas da cultura dos índios aparecem na demarcação do termo - "para o norte até o lugar chamado Hipu do Riacho Acarape...buscando o nascente até a fazanda chamada Humari, e para a parte do poente...todas as serras que desaguam as suas aguas para o dito Xoró" (REGISTRO..., 1891, p. 269).

É interessante mencionar que, a tratadística portuguesa do século XVI também enfatizava os aspectos utilitários do território como elementos que compunham a "conveniência" do lugar. De acordo com Rodrigo Almeida Bastos (2014, p. 72), o tratado de António Rodrigues listava nove conveniências, ou razões, a serem consideradas na escolha do sítio para a construção de povoações: i) boa região; ii) bons ares; iii) boas águas; iv) boas pastagens; v) terras aptas para a produção de mantimentos; vi) matas para lenha; vii) evitar terrenos entre serras e vales; viii) sítios a serem vistos de longe e ix) espaços de fácil acesso. Parece plausível, portanto, que o engenheiro Custódio Francisco de Azevedo conjugou informações obtidas na leitura da tratadística portuguesa com o território herdado dos indígenas, sendo visível, como veremos, na forma e na localização da vila de Montemor.

O desenho das vilas planificadas durante a Ilustração comungava princípios estéticos oriundos do Renascimento. Contudo, à forma urbis atribui-se representações próprias da cultura do Iluminismo, na qual a utopia da cidade ideal alinha-se a valores de civilidade (ARAUJO, 1998, p. 63). Na esteira dos estudos de Renata Araujo (1998) e Beatriz Bueno (2011), cabe recordar que a realização urbana praticada no período pombalino buscou dosar pragmatismo e idealismo utópico. Para Araujo (1998, p. 63), o urbanismo pombalino apresenta-se como a mais eloquente manifestação do pragmatismo, seja pelo uso do desenho de Lisboa (pós terremoto de 1755) e da técnica da engenharia militar, como pela adesão ao ideário discursivo de espaço civilizador. Bueno (2011, p. 631), por seu turno, aborda o desenho geométrico das vilas do Setecentos como resultado de um processo dialético em que o engenheiro militar, ou outro oficial da Coroa responsável pelo projeto, combina teoria e práxis. O projeto seria o resultado de um atento exame da envolvente, da atividade de levantamento, do arruamento dos chãos de terra e do ato de imaginar o edifício ou a forma urbana.

Assim como a vila de Assunção, o projeto de Montemor o Novo da América foi "traçado" em texto, no "Termo da Demarcação e Assignação do Terreno". O arquiteto cearense José Liberal de Castro (1999, p. 35-81), em artigo publicado na Revista do Instituto do Ceará, 
analisou com todo o cuidado o método empregado na implantação da vila, analisando a métrica e os significados intrínsecos alinhados ao ideário ilustrado de construção de cidades. Em 2 de abril de 1764, o ouvidor Victorino Soares Barbosa e o engenheiro Custódio Francisco de Azevedo deram início aos trabalhos de demarcação do termo, do rossio, da praça e dos chãos de terra da vila. $O$ engenheiro trouxe consigo uma prancheta ou círculo dimensório a fim de transpor do papel ao terreno as medidas do desenho imaginado (REGISTRO..., 1891, p. 265). Observa-se que a forma urbana se originou do levantamento topográfico do sitio no qual deveria se acomodar o desenho teórico convertido concretamente em vila no território (ARAUJO, 1998, p. 42).

Primeiramente, uma área retangular de 165 braças de comprido por 135 braças de largura foi definida e, em seu interior, uma praça de $80 \times 40$ braças foi estabelecida. A praça funcionaria como elemento balizador das etapas ulteriores de arruação e determinação dos lotes das moradas e dos edifícios públicos. Às moradias destinaram-se terrenos de 30x30 palmos, enquanto que à casa de câmara e demais construções públicas lotes de 60x60 palmos (REGISTRO..., 1891, p. 266). É visível a relação de proporção geométrica entre ambos os lotes. A igreja matriz, centralizada num dos lados da praça, e "ponto de fuga" da perspectiva da povoação, deveria ser fabricada em terreno de $80 \times 40$ palmos, deixando 10 palmos de cada lado da igreja reservados para futura ampliações ou reformas estruturais. Quanto à "rua principal da mesma praça", foi fixada a medida de 85 palmos de largura e para a travessas e demais ruas paralelas a dimensão de 40 palmos. Na rua principal, nas travessas e ao redor da praça foram previstas 154 moradas de casas (REGISTRO..., 1891, p. 267). O "desenho por escrito" imaginado para Montemor se aproxima daquele proposto para a vila de São José de Mipibu (figura 2) no tocante à configuração da praça, da localização da igreja, e com especial relevo para a rua central perpendicular à fachada principal do templo.

Figura 2 - Planta da vila de São João de Mipibu, 1762.

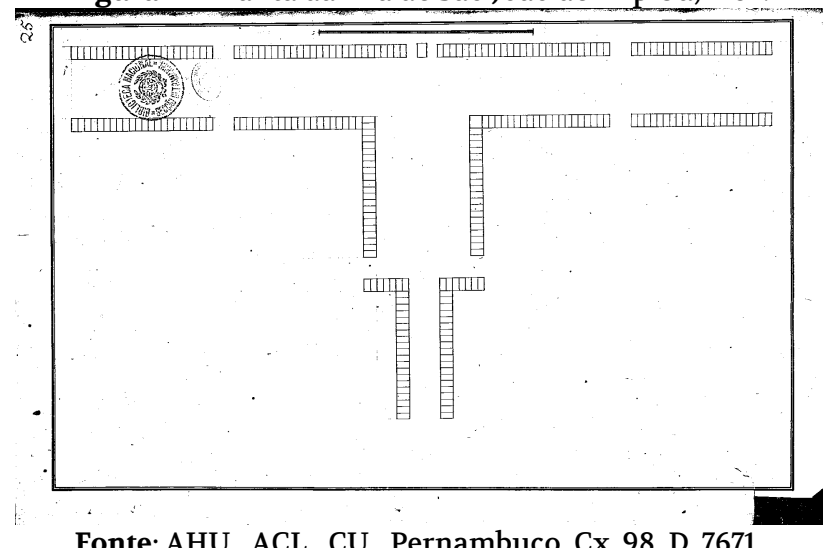

Oficio do governador da capitania de Pernambuco, Luís Diogo Lobo da Silva, a Francisco Xavier de Mendonça Furtado, sobre a diligência do ouvidor das Alagoas, Manoel de Gouveia Álvares, e o Juiz de Fora, Miguel Carlos Caldeira de Pina Castelo Branco, para a instalação das novas vilas de índios.. 
Determinados elementos preexistentes no lugar ajudaram o engenheiro Custódio de Azevedo a definir o desenho da vila. Devido à inclinação e à sinuosidade de um caminho desenvolvido logo atrás da igreja matriz, o eixo imaginado para a praça foi rompido. A igreja, por seu turno, estava "solta" na praça, em vez de sua fachada seguir o alinhamento proposto pelo documento régio. A "rua principal", eixo de simetria do projeto, apresenta-se com desvio angular ultrapassado os $90^{\circ}$ determinados. $O$ resultado final do desenho de Montemor o Novo traduz o pragmatismo dos envolvidos em dar corpo às recomendações (geo)métricas apresentadas no "Termo de demarcação e assignação do terreno". Mesmo com esses "desvios", a forma urbis não ficou comprometida conforme se vê na planta esboçada, em 1860, pelo botânico Francisco Freire Alemão (figura 3). No desenho, os elementos constitutivos da morfologia urbana da vila de índios, isto é, a grande praça, a dimensão da rua principal, a linearidade e a padronização das fachadas das moradias (cada uma com 30 palmos $=6,60 \mathrm{~m}$ ) aludem o esforço do engenheiro militar e dos oficiais régios de efetivar a normativa enviada de Lisboa.

Figura 3 - Planta da cidade de Baturité (antiga vila de Montemor o Novo da América), 16 de fevereiro de 1860.

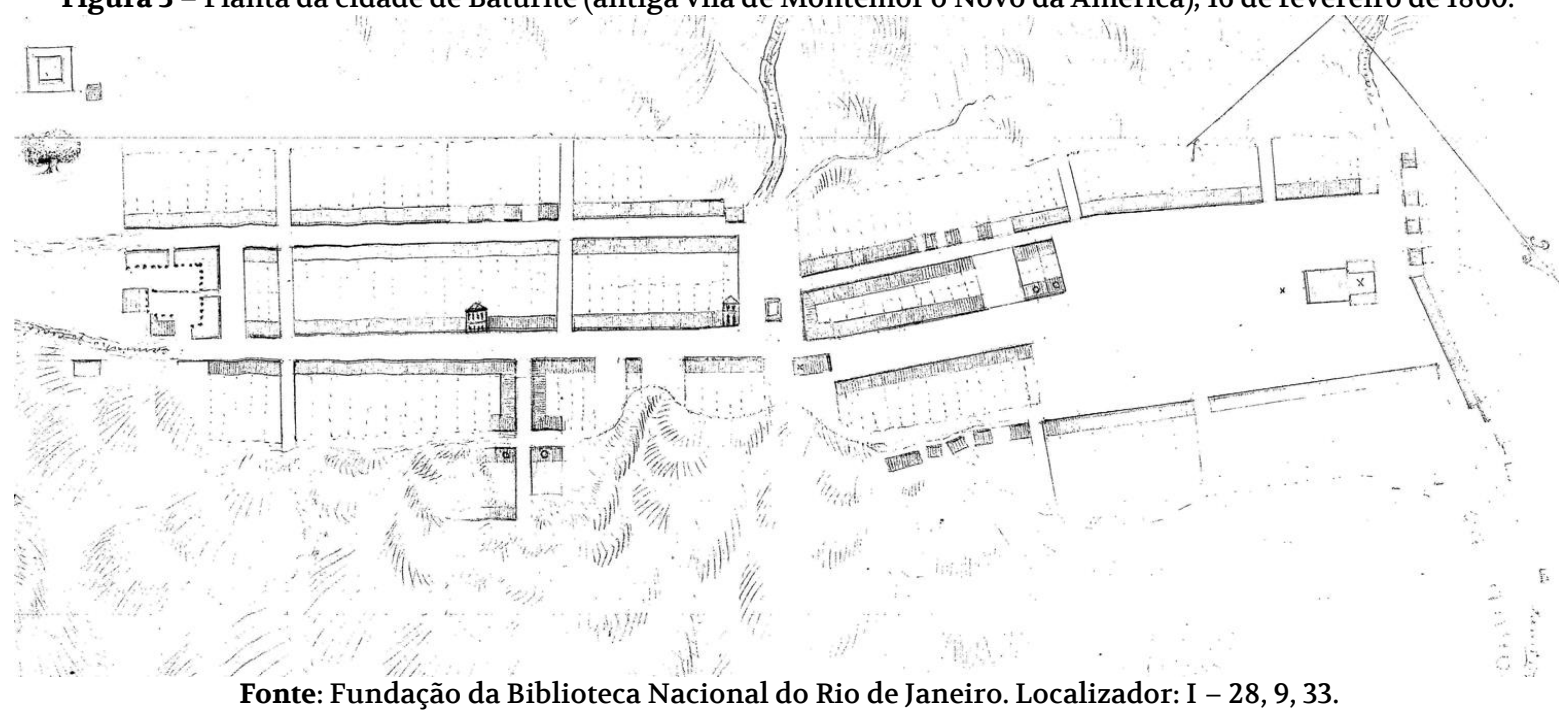

Ainda na capitania do Ceará Grande, o projeto da vila Real do Crato (antes missão capuchinha do Miranda) apresentou preceptivas plásticas similares aos demais núcleos urbanos supracitados. Em 21 de junho de 1764, as atividades de demarcação da vila, do rossio e do termo foram levadas a cabo pelo juiz de fora de Pernambuco, Miguel Carlos Caldeira de Pina Castelo Branco, o mesmo ator que havia instalado a vila de índios de Portalegre, situada na capitania do Rio Grande. A carta régia que determinou a forma urbana de Crato previa "alinham. ${ }^{\text {to }}$ da configuração e forma, com q' havia de fazer o arruamento" (Fundação da Biblioteca Nacional, Localizador: I - 28, 09, 010). Os trabalhos de arruamento deviam 
começar pela igreja utilizando o sistema de cordeamento ${ }^{8}$. A praça e os chãos de terra destinados às casas regulavam-se "pela igreja q' nella existe arruinada a qual tem de frente 50 palmos, e 100 palmos de fundo, se deixarão 20 palmos de área na frente de seus dois lados, em cada hum o que pudesse ser necessário para o tempo adiante vindo-se a fazer de novo como carece" (Fundação da Biblioteca Nacional, Localizador: I - 28, 09, 010). Naquele momento, optou-se por uma praça quadrada medindo 30 x 30 braças. Já o rossio, ou área da vila reservada ao uso comum dos moradores e ampliação material da vila, teria 300 braças em quadra. Crato, assim, se fez no chão, segundo a metodologia pragmática de desenhar vilas adaptadas às condicionantes geográficas locais e ao território herdado.

É provável que Pina Castelo Branco tenha cordeado a vila de Crato em consonância com as ordens expedidas da Coroa, conferindo ao seu traçado a regularidade imaginada. Não obstante, os índios e o Diretor edificaram casas de taipa cobertas de palha, as quais, para o ouvidor José da Costa Dias e Barros, eram arquiteturas que deformavam o prospecto da povoação, "indignas de (h)abitação de homens, e desviadas do devido alinham. ${ }^{\text {to }}$ ao mesmo tempo q' na creasão da mesma $V^{\text {a }}{ }^{\prime}$ forão estabelessidas todas as boas providencias de medisoens, alinham. ${ }^{\text {tos }}$ e abertudas das ruas" (AHU_Ceará, Cx. 9, D. 564). Para "remediar" o quadro, Dias e Barros redigiu, em 1778, o Provimento sobre o regulamento e aforamento das cazas da vila do Crato, documento primoroso formado por sete parágrafos com temas voltados à remodelação do desenho de Crato e ao aforamento das casas de acordo com a localização e os materiais empregados na construção.

No primeiro parágrafo do Provimento, os oficiais da Câmara foram exortados a edificar suas casas com, no mínimo, quatro braças de frente, "e no interior e fundo da aria farão ao q' lhe pareser; pena de pagada cada hum executivam. . $^{\text {te }} \mathbf{6 0 0 0} \mathrm{rs}$. annuaes no fim de cada ano" (AHU_Ceará, Cx. 9, D. 564). De partida, as recomendações do ouvidor envolviam aqueles elementos que, pelo seu aspecto moral, deveriam influenciar a civilização dos índios. A "deformidade" e "indignidade" do conjunto arquitetônico da vila de Crato motivou a escrita do segundo inciso, no qual numa espécie de "renascimento" da paisagem urbana deveria atingir uma imagem ideal de aparência definida por doutrinas estéticas de regularidade e simetria:

Todas as pessoas q' tem cazas de palha, ou ainda de telha desformes e indignas, as formarão e reedificarão de novo, ou as largarão da sua mão a q. ${ }^{\mathrm{m}}$ as quizer reedificar com as condisoens abaixo extabelecidas no precizo termo de todo este prez. ${ }^{e}$ ano; pena de ficarem os xãos devolutos a Camara $\mathrm{p} .{ }^{\mathrm{a}}$ as dar de foro a quem os pretender: mas isto se

\footnotetext{
${ }^{8}$ O dicionário de Raphael Bluteau atribui o seguinte ao verbete "cordear": "medir alguma coisa com uma corda". Nesse sentido, a cordeação seria a técnica empregada para traçar o desenho da vila de maneira pragmática, diretamente no terreno. Ver Bluteau (1728, p. 546).
} 
entenderá daquelas cazas q' se achão citas no alinham. ${ }^{\text {to }}$ q' deixo formado das ruas e da Prasa. Similhantem. ${ }^{\text {te }}$ todos os moradores q' tiverem as cazas ou mais adiantadas, ou mais recolhidas do determinado alinham. ${ }^{\text {to }}$ serão obrig. ${ }^{\text {dos }}$ a cordalas ou a hir enxer o terreno, e formar o prospecto das mesmas cazas no alinham. ${ }^{\text {to }} \mathrm{q}$ ' lhe he competente e confrontante, e isto no referido termo e com a sobred. ${ }^{\mathrm{a}}$ pena (AHU_Ceará, Cx. 9, D. 564).

Em seguida, o parágrafo terceiro determinou os materiais que as moradias deveriam ser construídas ou reformadas - "tijolo ou adobe cru ligado com barro formando primr. ${ }^{\circ}$ as paredes com bons paus mestres a pique, rebocadas de cal e caiadas" (AHU_Ceará, Cx. 9, D. 564). Cada casa teria 12 palmos (2,64 m) de altura com fachada composta por janelas de 5 palmos de altura e 4 palmos e meio de largura $(1,10 \times 0,99 \mathrm{~m})$, já as portas teriam vão-luz de 10 palmos de altura e 5 de largura $(2,2 \times 1,10 \mathrm{~m})$. As janelas estariam niveladas com a altura da porta para harmonizar o "prospecto" da rua. Rejeitava-se a palha em favor da telha como material de cobertura. A "sumeira", ou o que hoje se conhece como beiral do telhado, estaria afastada 3 palmos $(0,66 \mathrm{~m})$ da parede da fachada, com o propósito de evitar "copiar" ou "alpendre" que escurece a casa deixando-a disforme ou sem a formosura do arranjo ritmado por porta-janela. Em compensação, "poderão ter copiares aquelas cazas que ficão no lado das ruas $q^{\prime}$ correm Norte Sul olhando $\mathrm{p}^{\mathrm{a}}{ }^{\mathrm{o}}$ o Nacente, donde geralm. ${ }^{\text {te }}$ vem os xuveiros" (AHU_Ceará, Cx. 9, D. 564).

O quarto parágrafo arrola o valor dos foros - $80 \mathrm{rs}$. por braça de dez palmos. $\mathrm{O}$ aforamento seria lançado num caderno de tombo guardado na Câmara e de responsabilidade do escrivão. Ali, seriam especificados os nomes dos donos das casas e o respectivo tributo pago anualmente. No sexto inciso, Dias e Barros destina o lado oriental da praça, " $q$ ' fica demarcado fronteiro a Igreja", para uso exclusivo da população indígena, "os quaes não poderão edificar em outra alguã parte” (AHU_Ceará, Cx. 9, D. 564). Nesse aspecto, a autoridade régia determina uma espécie de zoneamento, isolando os indígenas no lado oriental da praça. Finalmente, o último ponto do Provimento ordenou, a todos os oficiais do concelho, que o documento fosse lido em dia de vereação, assim como o tornasse público "para não alegarem de ignorancia...os moradores desta V. a” (AHU_Ceará, Cx. 9, D. 564).

O termo de Crato foi definido pelo juiz de fora Miguel Carlos Caldeira de Pina Castelo Branco. Em geral, o termo das vilas de índios consistia de território muito extenso, definido pelos contornos das ribeiras ou por montanhas. No entanto, houve algumas exceções, como as vilas de Assunção e Santa Maria, situadas em ilhas do rio São Francisco, cujo espaço da circunscrição administrativa se resumia à própria ilha. Além dessas, a Coroa estipulou como termo e patrimônio da Câmara das vilas de Soure, Pombal, Mirandela e Tomar, implantadas nos sertões de Baixo da capitania da Bahia, uma área de uma légua em quadra destinada à 
agricultura de subsistência (Fundação da Biblioteca Nacional, Localizador: 08, 02, 022). Essa dimensão talvez se refira à sesmaria de uma légua em quadra concedida, por D. Pedro II, às aldeias missioneiras com mais de 100 casais no alvará de 23 de novembro de 1700 (Fundação Biblioteca Nacional, 1908, p. 393).

Qualquer que seja a origem, os termos das vilas de índios dos sertões da Bahia se configuraram no espaço de maneira particular. Eles foram demarcados dentro das circunscrições do concelho ou da freguesia a que pertenciam antes da elevação à condição de vila. A esse respeito, o arcebispo da Bahia, D. Fr. Antônio Corrêa, os descrevia como "encravados nas freguesias de brancos" (Fundação Biblioteca Nacional, 1916, p. 160), que em sentido metafórico, se aproxima a uma certa "topofagia", ou seja, o termo da "vila de brancos" engolia o termo da "vila de índios" (figura 4). A carta régia de 12 de maio de 1798 , que extinguiu o Diretório dos Índios, retirou as sesmarias dos indígenas confirmadas no alvará de 23 de novembro, colocando-as disponíveis para a venda (KANTOR, 2010, p. 309).

Figura 4 - Exemplo de "topofagia". O termo da vila de Tomar "encravado" na freguesia de Nossa Senhora dos Campos do Rio Real. Imagem retirada da "Carta topographica da provincia de Sergipe, 1831.

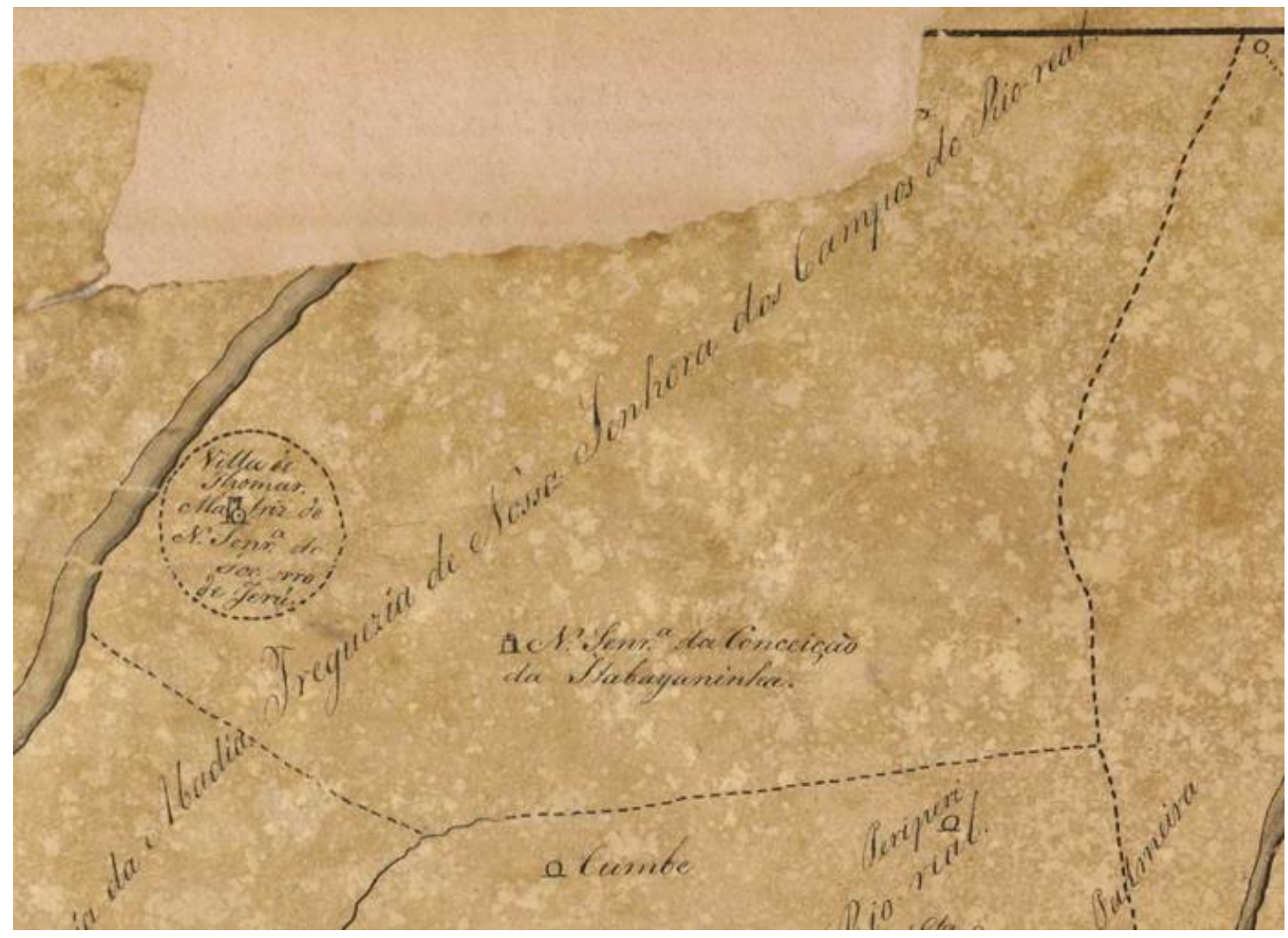

Fonte: Carta topográfica da província de Sergipe, 1831. Fundação Biblioteca Nacional do Rio de Janeiro(FBN). Seção Cartográfica. Mapa disponível em http//www.bn.br. Acesso em 09 mar. 2016 


\section{Considerações finais}

As reformas territorial e urbana dos sertões das capitanias do Norte e do Estado do Maranhão passaram a entrar na agenda da Coroa portuguesa no final do século XVII. Datam desse período a emissão de cartas régias e alvarás com teor de lei que visavam a redistribuição das sesmarias incultas, a doação de terras para as aldeias missioneiras e a criação das primeiras paróquias mais interiorizadas.

As políticas de urbanização da Coroa portuguesa tiveram sua maior interferência no espaço a partir da fundação das primeiras vilas. Elas reestruturaram os sertões de lugares indefinidos em territórios demarcados, controlados pela câmara formada por oficiais nomeados pelo rei ou por seus representantes diretos. Contudo, até por volta de 1756, a quantidade de vilas era reduzida se comparada com a rede urbana formada ao longo da costa atlântica ou na capitania de Minas Gerais, onde o adensamento populacional, por vezes, justificava a criação de novas municipalidades.

Esse quadro modifica-se quando um amplo projeto de reforma territorial foi levado a cabo por Sebastião José de Carvalho e Melo e seu meio-irmão Francisco Xavier de Mendonça Furtado: pensava-se a América portuguesa em sua totalidade, como um grande laboratório onde seriam ensaiados projetos de reforma territorial e social. Com efeito, o número de vilas aumentou em sertões de fronteiras, como os da capitania de Mato Grosso, São José do Rio Negro e São Paulo. Cresceu, inclusive, em regiões onde as ordens religiosas atuaram de maneira significativa, como no Piauí, nos sertões da Bahia, na capitania do Ceará Grande e nas margens do rio São Francisco.

No âmbito social, a civilização indígena e sua liberdade pautaram leis que incluíram os nativos no sistema administrativo das vilas, além da clara repercussão da reforma dos sertões realizada em meados do Setecentos. As cartas regias de fundação de vilas de índios previam o ordenamento espacial - com casas construídas em boa perspectiva e com a "formosura" das fachadas - como instrumento ideológico de civilização e controle da população nativa.

Por outro lado, os executores das ordens régias, cônscios da praticidade de "riscar povoações no chão", adaptaram a forma urbis das vilas às preexistências. Ao fazerem isso, eles reconheciam o território de vivência indígena como basilar à reestruturação urbana em execução. Por isso, foi comum a implantação dos núcleos urbanos nas proximidades das antigas aldeias ou missões religiosas. Sem esquecer que os contornos do termo e rossio das 
vilas foram orientados por marcos naturais cuja toponímia evocava vocábulos de origem indígena. Nesse sentido, como os novos estudos sobre a história da urbanização brasileira vêm demonstrando, parece oportuno incluir o índio e o negro na formação espacial da América portuguesa, explicitando que a nossa urbanização não se tratou de um esforço unilateral, exclusivamente europeu, mas comungou os esforços de diferentes saberes e culturas.

\section{Fontes documentais}

Arquivo Histórico Ultramarino. Administração Central. CARTA do governador da capitania de Pernambuco, Henrique Luís Pereira Freire de Andrada, ao rei (D. João V), sobre a representação dos índios Tapuias em que se queixam dos maus tratos dos que se afastam da conversão, e a respeito de suas terras e do cativeiro, que tendo sito consultada pela Mesa da Consciência, remeteu para o Conselho Ultramarino a cópia da Junta das Missões e a distribuição das aldeias. Conselho Ultramarino_Pernambuco, Cx. 55, D. 4767.

Arquivo Histórico Ultramarino. Administração Central. Carta do vice-rei e capitão general do Estado do Brasil, conde de Sabugosa, Vasco Fernandes César de Menezes ao rei (D. João V), recomendando que se crie cargo de ouvidor geral para Rio de Contas, Jacobina e Rio São Francisco.. Conselho Ultramarino_ Bahia, Cx. 21, D. 1842.

Arquivo Histórico Ultramarino. Administração Central. Carta régia dirigida ao arcebispo da Bahia, em que lhe ordena que transformasse as missões em parochias e para ellas nomeassem párocos do Habito de São Pedro. Conselho Ultramarino_Bahia, Cx. 20, D. 3635.

Arquivo Histórico Ultramarino. Administração Central. CARTA régia dirigida ao vice-rei conde dos Arcos, na qual se lhe ordena a execução do antecedente alvará e o estabelecimento civil dos índios e que se fizesse erigir em vilas e lugares, com a denominação das terras do Reino, as aldeias que eram habitadas pelos referidos indios. Conselho Ultramarino_Bahia, Cx. 20, D. 3634.

Arquivo Histórico Ultramarino. Administração Central. Consulta do Conselho Ultramarino ao rei (D. João V), sobre a solicitação que o ouvidor geral da capitania do Maranhão, Francisco Raimundo Morais Pereira, fez para se criar, nos distritos de Parnaíba, Aldeias Altas e Mearim, os cargos de juiz ordinário com seu escrivão e meirinho. .Conselho Ultramarino_ Bahia, Cx. 29, D. 2978. 
Arquivo Histórico Ultramarino. Administração Central. Ofício do governador do Piauí, João Pereira Caldas, ao secretário de Estado da Marinha e Ultramar, Francisco Xavier de Mendonça Furtado, sobre as desordens praticadas pelo vigário de Oeiras do Piauí, padre Dionísio José de Aguiar, e pelo vigário da vila de Parnaguá, Francisco da Costa e Silva; acerca da nova organização das aldeias de índios na sua capitania, à semelhança do que é descrito pelo Diretório. Conselho Ultramarino_Piauí, Cx. 10, D. 589.

Arquivo Nacional da Torre do Tombo. ANTT. Breves Pontifícios e cartas régias sobre os índios, comércio e liberdade de suas pessoas.. Feitos Findos, Casa da Suplicação, liv. 33.

Arquivo Nacional da Torre do Tombo. ANTT. Carta do governador do Maranhão, Joaquim de Mello e Povoas, a Francisco Xavier de Mendonça Furtado sobre o estado da capitania do Maranhão.. Ministério do Reino, mc. 601, cx. 704, n. 72.

Arquivo Nacional da Torre do Tombo. ANTT. Instrumentos de descrição dos Fundos e Colecções do Arquivo Nacional da Torre do Tombo.

Biblioteca da Nacional de Portugal. Registro das cartas em geral das duas capitanias do Pará e Rio Negro, que escreve o Ill. $^{\mathrm{mo}} \mathrm{e}$ Ex. ${ }^{\mathrm{mo}}$ Sr. Francisco Xavier de Mendonça Furtado, Governador e Capitão General do Estado do Grão Pará e Maranhão. Correspondência official (1754-1758). Colecção Pombalina.

DIRECTORIO que se deve observar nas povoaçoens dos Indios do Pará, e Maranhaõ Emquanto Sua Magestade não mandar o contrario. Lisboa: Officina de Miguel Rodrigues, 1758. Disponível em: <http://www.bnportugal.pt $>$. Acesso em: 25 out. 2016.

Fundação Biblioteca Nacional. Exposição do Arcebispo D. Fr. Antonio Correa, sobre as igrejas, parochos e missões do Arcebispado da Bahia. 1916, Rio de Janeiro. Anais... Rio de Janeiro: Officinas de Artes Graphicas da Bibliotheca Nacional, 1916. v 36, p. 159-160.

Fundação Biblioteca Nacional. Notas sobre a criação da vila do Crato extraídas do livro de inventário dos bens da igreja da missão de Jucá. Manuscrito da Fundação da Biblioteca Nacional do Rio de Janeiro. Localizador: I - 28, 09, 010.

Fundação Biblioteca Nacional. Noticia e informações das vilas e aldeias das freguesias dos sertões de baixo da capitania da Bahia. Manuscrito da Fundação da Biblioteca Nacional do Rio de Janeiro. Localizador: 08, 02, 022.

Fundação Biblioteca Nacional. Registro da mudança da vila da ilha de Assunção para a ilha de Pambú. Manuscrito da Fundação da Biblioteca Nacional. localizador: I - 2, 3, 35.

Fundação Biblioteca Nacional. Relação das Aldeas que há no destricto do Governo de Pernambuco, Paraíba, e mais capitanias anexas, de diversas nações de Índios. In Livro 
composto, principalmente de cartas, portarias e mapas versando sobre vários assuntos, relacionados com a administração de Pernambuco e das capitanias anexas, tais como: índios, estabelecimento de vilas e aldeias. Rio de Janeiro. Localizador: I - 12, 3, 34.

Fundação Biblioteca Nacional. Sobre se tocarem differtentes materias pertencentes a Missões, indios e missionarios. Anais... Rio de Janeiro: Officinas de Artes Graphicas da Bibliotheca Nacional, 1908. v. 28, p. 397-399.

Gabinete de Estudos Arqueológicos de Engenharia Militar (GEAEM). Direção de Serviços de Engenharia. Carta Topographica aonde se compreendem as Capitanias de que se compoem ao prezente o Governo de Pernambuco; oferecida ao Ill. ${ }^{\text {mo }}$ e Ex. ${ }^{\text {mo }}$ S. $^{\text {r }}$ Fran. $^{\text {co }} \mathrm{X}$. de M. . $^{\text {a }}$ Furtado, do Conselho de S. Mag. ${ }^{e}$ Fidelissima, Ministro, e Secretario de Estado da Marinha e Conquistas, 1766, por José Gonsalves da Fonseca. GEAEM.. Direção de Serviços de Engenharia. Mapoteca, Doc. 4586-3-38-5.

LEY, por que V. Mag. ${ }^{\text {de }}$ há por bem restituir aos Índios do Grão-Pará, e Maranhão a liberdade das suas pessoas, e bens, e commercio - na forma que nella se declara. Lisboa, 1755. Disponível em: <http://www.bnportugal.pt >. Acesso em: 18 nov. 2010.

REGISTRO dos Autos de ereç̧ão da real villa de Monte-mór o Novo da América, na capitania do Ceará Grande. Revista do Instituto do Ceará, Fortaleza, ano 5, p. 82-300, 1891.

\section{Referências}

ALMEIDA, Rita Heloisa. $O$ diretório dos índios: um projeto de civilização no Brasil do século XVIII. Brasília: Ed. UnB, 1997.

ARAUJO, Renata Malcher de. As cidades da Amazónia no século XVIII: Belém, Macapá e Mazagão. Porto: Faup Publicações, 1998.

ARAUJO, Renata Malcher de. A razão na selva: Pombal e a reforma urbana na Amazônia. Revista Camões, Lisboa, n. 15/16, p. 151-165, 2003.

ARAUJO, Renata Malcher de. Desenhar cidades no papel e no terreno: cartografia e urbanismo na Amazónia e Mato Grosso no século XVIII. In: OLIVEIRA, Francisco Roque; VARGAS, Héctor Mendonza (Coord.). Mapas de metade do mundo: a cartografia e a construção territorial dos espaços americanos: séculos XVI a XIX. Lisboa: Centro de Estudos Geográficos - UL, 2010. 
ARAUJO, Renata Malcher de. Às portas do paraíso. Mais que aldeia, menos que vila, o purgatório da utopia. In: ACCIAIUOLI, Margarida (Org.). Arte \& utopia. Lisboa: CHAIAUE/DINÂMICA', 2013.

BASTOS, Rodrigo Almeida. A arte do urbanismo conveniente: o decoro na implantação de novas povoações em Minas Gerais na primeira metade do século XVIII. Florianópolis: UFSC, 2014.

BELLOTO, Heloísa Liberalli. Política indigenista no Brasil colonial (1570-1757). Revista do Instituto de Estudos Brasileiros, São Paulo, n. 29, p. 49-60, 1988.

BLUTEAU, Raphael. Vocabulario portuguez \& latino: aulico, anaomico, architectonico...Coimbra: Collegio das Artes da Companhia de Jesus, 1728.

BUENO, Beatriz P. Siqueira. Desenho e desígnio: o Brasil dos engenheiros militares (15001822). São Paulo: Edusp, 2011.

CASTRO, José Liberal de. Urbanização pombalina no Ceará: a paisagem da vila de Montemor-o-Novo da América. Revista do Instituto do Ceará, Fortaleza, n. 113, p. 35-81, 1999.

DELSON, Roberta M. Novas vilas para o Brasil - colônia: planejamento espacial e social no século XVIII. Brasil: Alva, 1997.

DERNTL, Maria Fernanda. Método e arte: urbanização e formação territorial na capitania de São Paulo, 1765 - 1811. 2010. Tese (Doutorado em Arquitetura e Urbanismo) - Faculdade de Arquitetura e Urbanismo, Universidade de São Paulo, São Paulo, 2010.

GIANESELLA, Rubens Ramos. Paisagens no tempo: vilas litorâneas paulistas. 2008. Dissertação (Mestrado em Arquitetura e Urbanismo) - Faculdade de Arquitetura e Urbanismo, Universidade de São Paulo, São Paulo, 2008.

KANTOR, Iris. Usos geopolíticos da memória toponímica na formação do Estado brasileiro (1750-1850). In: OLIVEIRA, Francisco Roque de; VARGAS, Héctor Mendonza. Mapas de metade do mundo: a cartografia e a construção territorial dos espaços americanos: séculos XVI a XIX. Lisboa: Centro de Estudos Geográficos da Universidade de Lisboa, 2010.

LEITE, Serafim. História da Companhia de Jesus. Tomo III. Rio de Janeiro: Imprensa Nacional, 1945.

NANTES, Padre Martinho de, O. F. M. Cap. Relação de uma missão no rio São Francisco: relação sucinta e sincera da missão do padre Martinho de Nantes, pregador capuchinho, missionário apostólico no Brasil entre os índios chamados cariris. 2 ed. São Paulo: Editora Nacional, 1979. 
LOPES, Fátima Martins. Em nome da liberdade: as vilas de índios do Rio Grande do Norte sob o Diretório pombalino no século XVIII. 2005. Tese (Doutorado em História do NorteNordeste) -Universidade Federal de Pernambuco, Recife, 2005.

MARTIN, Gabriela. Arqueologia nas missões religiosas do Nordeste do Brasil. Cadernos de Estudos Sociais, Recife, v. 6, n. 1, p. 165-180, 1990.

MARTINS, F. A. Oliveira. Um herói esquecido (João da Maia da Gama). Lisboa: Divisão de Publicações e Biblioteca Agência Geral das Colónias, 1944.

MOREIRA, Rafael. A arte de ruação e a cidade luso-brasileira. Cadernos LAP, São Paulo, n. 37, jan./jun. 2003.

PAPAVERO, Nelson et al. As "adnotationes" do jesuíta Johann Breuer sobre a história natural da missão de Ibiapaba, Ceará (1789). Arquivos de Zoologia, São Paulo, v. 42, n. 3, p. 133-159, 2011.

PERRONE-MOISÉS, Beatriz. Índios livres e índios escravos: os princípios da legislação indigenista do período colonial (séculos XVI a XVIII). In: CUNHA, Manuela Carneiro (Org.). História dos índios no Brasil. São Paulo: Companhia das Letras, 1992.

RODRIGUES, Isabel Vieira. A política de Francisco Xavier de Mendonça Furtado no norte do Brasil (1751-1759). Oceanos, Lisboa, n. 40, out./dez. 1999.

Recebido em 12/01/2018

Aprovado em 22/05/2018 